\title{
Evaluation of the effects of different freezing and thawing methods on the quality preservation of Pleurotus eryngii
}

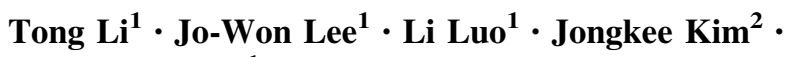 \\ BoKyung Moon ${ }^{1}$
}

Received: 20 November 2017 / Accepted: 21 February 2018/Published online: 6 March 2018

(C) The Korean Society for Applied Biological Chemistry 2018

\begin{abstract}
The individually quick-frozen (IQF) method is used to produce high-quality frozen food by freezing an individual piece of food separately from the remaining food. In this study, the effect of various freezing and thawing combinations on the quality preservation of Pleurotus eryngii (king oyster mushroom) was investigated. For this purpose, diced and mini $P$. eryngii mushrooms were frozen by natural freezing $\left(\mathrm{NF},-20^{\circ} \mathrm{C}\right)$ or IQF $\left(-62.5{ }^{\circ} \mathrm{C}\right.$ and speed $\left.8.23 \mathrm{~m} / \mathrm{s}\right)$ methods and thawed using three thawing methods-flowing water thawing (FT, $4{ }^{\circ} \mathrm{C}$ ), microwave thawing (MT, $620 \mathrm{~W}$ ), or natural air convection thawing (NT, $20 \pm 5{ }^{\circ} \mathrm{C}$ ). Quality characteristics, such as thawing loss, texture, water holding capacity, color, microstructure, and sensory quality, were evaluated. MT showed the most rapid thawing time, followed by FT and NT for all the samples. The results showed that thawing curve, water holding capacity, and hardness of IQF samples were better than those of NF samples after NT, FT, and MT. Scanning electron microscopy analysis revealed that cell integrity of the IQF sample was better than that of the NF sample. MT is the fastest of the thawing methods, but thawing after NF yielded a sample closest to the fresh mushroom sample. Therefore, when combined with NT, IQF minimized the quality changes in frozen diced and mini $P$. eryngii mushrooms. This study showed that the
\end{abstract}

BoKyung Moon

bkmoon@cau.ac.kr

1 Department of Food and Nutrition, Chung-Ang University, 72-1, Nae-ri, Daedeok-myeon, Anseong-si, Gyeonggi 456-756, Republic of Korea

2 Department of Integrative Plant Science, Chung-Ang University, 72-1, Nae-ri, Daedeok-myeon, Anseong-si, Gyeonggi 456-756, Republic of Korea
IQF technology can be used as a new preservation and distribution method of mushroom.

Keywords Freezing and thawing methods - Individually quick-frozen · Pleurotus eryngii · Quality changes · Scanning electron microscopy images

\section{Introduction}

Mushrooms are widely used in Asian countries because of their high food value and excellent medicinal value; they are also gaining increasing attention of researchers, especially in the prevention of certain diseases or improvement in health [1-3]. Pleurotus eryngii (king oyster mushroom) is widely used because of its culinary qualities, attractive texture, and flavor preferred by the consumers as well as its pharmaceutical properties. It is mainly cultivated in China and Japan, and its market share in Korea is higher than that of the other mushroom varieties [4-7].

It has been reported that only $45 \%$ of mushroom are used in their fresh form because fresh mushrooms are seasonal and have a short shelf life [8]. Therefore, it is necessary to determine a method to store them post-harvest $[9,10]$. Freezing, canning, or drying could extend the shelf life of fresh products and increase their seasonal availability and market accessibility $[8,11]$. The prevailing low temperature effectively weakens microbial and enzymatic activities and the respiration and oxidation of the ripened fruit or vegetable $[9,12]$. Therefore, in the food industry, freezing is one of the most important and effective processing technologies for preserving fruits and vegetables to maintain their quality and nutritional properties. Additionally, it is widely used as a post-harvest treatment of mushrooms [9, 13, 14]. However, in traditional air-blast 
freezing systems, severe damage is caused to the texture due to large ice crystals formed during slower block freezing [15]. Inappropriate freezing methods will lead to the formation of large ice crystals, which destroy the configuration of the cell wall of fresh products.

As compared to the slower block freezing, the individually quick-frozen (IQF) method, using cryogenic gases, lowers temperature of fruits and vegetables to their freezing point rapidly and retains cell integrity while hardly changing their nutritional quality and sensory characteristics $[9,11,16-18]$. Because of the advantages of IQF, this technology has been widely used in the treatment of fruits and vegetables such as frozen blueberries, peach, and green beans $[16,19,20]$. In addition, this freezing method was reported to slow down the rate of microbiological growth in frozen scallops and shrimps [21]. Nowadays, the demand of consumers for IQF products is considerably higher than that for general frozen products [22]. Generally, frozen food needs to thaw before processing and intake; thawing can influence product quantity directly or indirectly. Thus, freezing and thawing are equally important for consumers. Though various thawing methods, such as natural air convection thawing (NT), flowing water thawing (FT), or microwave thawing (MT) wave thawing, are used in daily life, natural defrosting and microwave thawing are the two most popular ways to thaw frozen products [11].

Singh et al. [10] reported that mushroom could keep its intact shape only for 1-3 days after harvest due to environmental changes. In addition, technologies commonly used to preserve mushroom such as freezing, canning, or drying showed restrictions on the texture and color of mushrooms storage [23, 24]. Therefore, it is necessary to develop a new technique to keep the texture, color of mushroom during storing. In this study, we aimed to determine the influence of different freezing and thawing methods on the quality characteristics, such as thawing curve, water holding capacity, thawing loss, texture, color, sensory evaluation, and microstructure, of $P$. eryngii. The results were collected and compared depending on different freezing and thawing conditions to explore the effective freezing and thawing processes to maintain the quality of P. eryngii mushrooms.

\section{Materials and methods}

\section{Materials}

Mature and mini P. eryngii mushrooms were obtained from a commercial orchard in Anseong, Gyeonggi, Korea. Mushrooms were pruned, cleaned, and selected for uniformity of shape, color, and size, and mature mushrooms were cut into $1.2 \times 1.2 \times 1.2 \mathrm{~cm}$ dices for freezing. Whole mini mushrooms were also used for freezing.

\section{Freezing and thawing process}

Pleurotus eryngii were frozen by either natural air convection freezing (NF) at $-20{ }^{\circ} \mathrm{C}$ or IQF at $-62.5^{\circ} \mathrm{C}$ (speed $8.23 \mathrm{~m} / \mathrm{s}$ ) according to the method described by Shim et al. [11]. When the core temperature of samples reached $-20^{\circ} \mathrm{C}$, the freezing process was stopped and they were stored using vacuum packing at $-20^{\circ} \mathrm{C}$. All frozen samples were thawed by one of the following three methods, NT at room temperature, FT at $4{ }^{\circ} \mathrm{C}$, or MT at $620 \mathrm{~W}$. A fiber optic temperature sensor (Hanyoung Nux, Incheon, Korea) was inserted into mushroom samples to monitor the temperature, and thawing was stopped when the core temperature of the samples reached $4{ }^{\circ} \mathrm{C}$.

\section{Water holding capacity and thawing loss analyses}

Water holding capacity and thawing loss analyses were performed according to Shim's method [11]. Dry gauze and approximately $1 \mathrm{~g}$ sample $\left(\mathrm{W}_{1}\right)$ were put into a falcon tube $\left(\mathrm{W}_{2}\right)$ and centrifuged $\left(4^{\circ} \mathrm{C}, 1500 \times g\right)$ using a centrifugal separator (Gyrozen, Deajeon, Korea) for $10 \mathrm{~min}$. After centrifugation, the mushroom sample was measured in the falcon tube and was marked as $\mathrm{W}_{3}$. The water holding capacity of all samples was calculated by the below-mentioned formula.

Water holding capacity $(\%)=\left[W_{1}-\left(W_{3}-W_{2}\right)\right] / W_{1} \times 100$.

The weight of samples before freezing was marked as $\mathrm{W}_{1}$ and that after thawing and dewatering was marked as $\mathrm{W}_{2}$. The thawing loss of samples was calculated by the below-mentioned formula, and the experiment was repeated 3 times similarly.

Thawing loss $(\%)=\left(W_{1}-W_{2}\right) / W_{1} \times 100$.

\section{Cutting force analysis}

A texture analyzer (TAHDi/500, TAHD Co. SMS, UK) was used to perform the cutting force for determining the hardness of thawed mushroom [11, 25, 26]. Each sample was placed individually on the base and was compressed once using a Warner-Bratzler shear blade with guillotine probe to give a complete compression-relaxation-tension profile curve. The experiment for each sample was repeated 10 times. The settings of the experiments were as follows: trigger load $500 \mathrm{~g}$, target distance $15 \mathrm{~mm}$, and speed $2.5 \mathrm{~mm} / \mathrm{s}$. Hardness (g) was recorded through cutting force values, which were obtained from the cutting force program. Cutting force test was repeated 10 times. The force- 
time deformation curves were obtained from each sample according to which the following parameters were quantified: Hardness $(\mathrm{g})$ is the peak force required for sample compressing. Texture Expert Excede v 4.13 (Stable Micro Systems Software) was used to process the data.

\section{Color analysis}

An UltraScan PRO colorimeter (Hunter Laboratory, Reston, VA, USA) was used to determine the color parameters [27]. Surface color of each sample surface was measured for $L^{*}$ (lightness); positive $\alpha^{*}$ corresponded to red color, otherwise to green color; the yellow color of $b^{*}$ expressed as positive, and blue color represents negative. Color values were measured, which were acquired at two different positions of each sample. Each analysis was repeated in triplicate.

\section{Microstructure analysis}

To visually determine the effect of different freezing and thawing methods as well as that of other external factors on the mushroom tissues, mini mushroom samples were adopted in this study. Each mini mushroom was subjected to scanning electron microscopy (SEM) to obtain a crosssectional structure (Hitachi-S-3400N, Hitachi Ltd. Tokyo, Japan). Accelerating voltage was set at $10 \mathrm{kV}$ for observing each sample. The SEM images were scanned at $1000 \times$ magnification.

\section{Sensory evaluation}

The sensory evaluation for thawed mushroom (frozen by NF and IQF and thawed by NT, FT, and MT) was performed by 30 panelists. The affective test for appearance, color, mushroom flavor, and overall preference of samples was assessed using a 7-point hedonic scale ( 7 denotes to 'like extremely,' while 1 denotes to 'dislike extremely'). Mushroom samples were numbered and distributed to tasters randomly. Panelists were asked to gargle before tasting. The panelists were asked to evaluate their degree of liking of mushroom samples.

\section{Statistical analysis}

Quantitative data are expressed as mean \pm standard deviation (SD) of triplicate measurements. Data were analyzed by one-way analysis of variance (ANOVA) and Duncan's multiple range test $(p<0.05)$ using SAS version 8.0 for Windows (SAS Inst. Cary, NC, USA).

\section{Results and discussion}

\section{Thawing curve}

Figure 1 shows the thawing curves of mini and diced mushrooms, which were processed by the three thawing methods. All the samples revealed that the thawing process slowed noticeably when the temperature was above $0{ }^{\circ} \mathrm{C}$. In case of NT, mini mushrooms frozen by NF took the longest thawing time of $42.48 \mathrm{~min}$, and those frozen by IQF took $38.56 \mathrm{~min}$ to reach $4{ }^{\circ} \mathrm{C}$. In case of diced mushrooms, samples frozen by IQF reached $4{ }^{\circ} \mathrm{C}$ faster compared with those frozen by NF. In FT, mini mushroom IQF and NF samples showed the same thawing curves; samples took $7 \mathrm{~min}$ to reach $4{ }^{\circ} \mathrm{C}$. However, the time consumed by diced mushrooms frozen by NF was longer than those frozen by IQF. Compared with NT samples, FT samples after IQF and NF take less time to reach $4{ }^{\circ} \mathrm{C}$. According to Shim et al. [11], FT was faster than NT because the velocity of heat in the tissue during flowing water thawing $\left(4^{\circ} \mathrm{C}\right)$ was faster than that during natural air thawing.

Compared with NT and FT, another thawing curve was observed in MT. MT was the fastest thawing method, and the temperature of IQF and NF mini mushrooms reached $4{ }^{\circ} \mathrm{C}$ in 1.2 and $1.4 \mathrm{~min}$, respectively. The thawing speed of IQF and NF diced mushrooms is faster than that of mini mushrooms by about $40 \mathrm{~s}$.

IQF samples take lesser time to thaw than NF samples do, because NF leads to the formation of a large ice crystal, which can slow down the thawing curve $[13,15]$. In this study, the pore diameter of IQF is smaller than that of NF. IQF, rather than NF, is considered as a better way to freeze samples for retaining cell integrity as well as maintaining the texture. These results were also shown in SEM findings.

\section{Water holding capacity and thawing loss analysis}

Figure 2 describes the water holding capacity and thawing loss of mini and diced mushrooms. In mini mushroom samples, no significant difference was noted in NT and FT after IQF and NF (Fig. 2A), whereas in case of MT, the water holding capacity of IQF samples (67\%) was higher than that in NF samples, and the thawing loss in IQF samples was lower than that in NF samples. According to Alvarez and Canet [28], rapid freezing time of vegetables can cause higher water holding capacity. In diced mushroom with NT, FT, and MT, the water holding capacity of IQF samples was significantly higher than that of NF samples (Fig. 2B). The thawing loss of IQF samples was significant lower than that of NF. The water holding capacity of NF samples was significantly lower than that of 


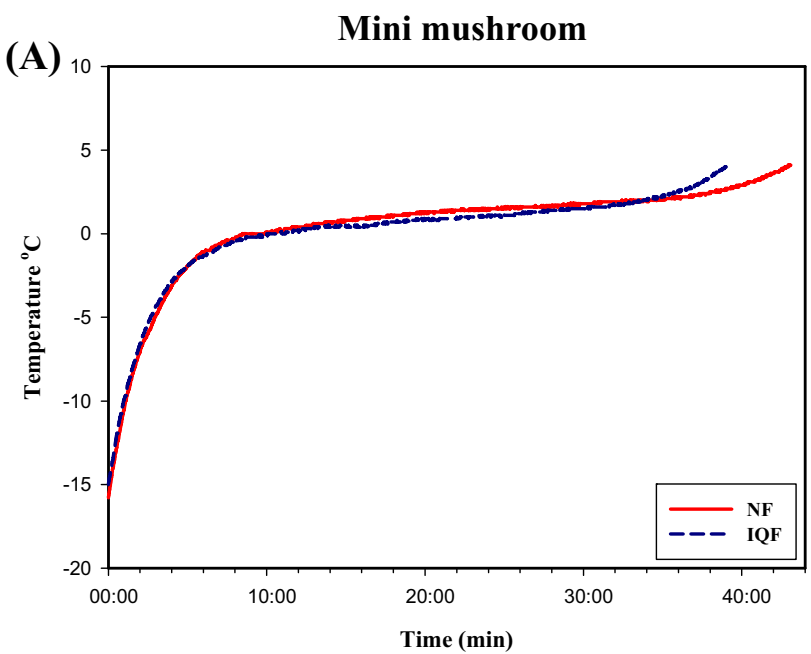

Diced mushroom

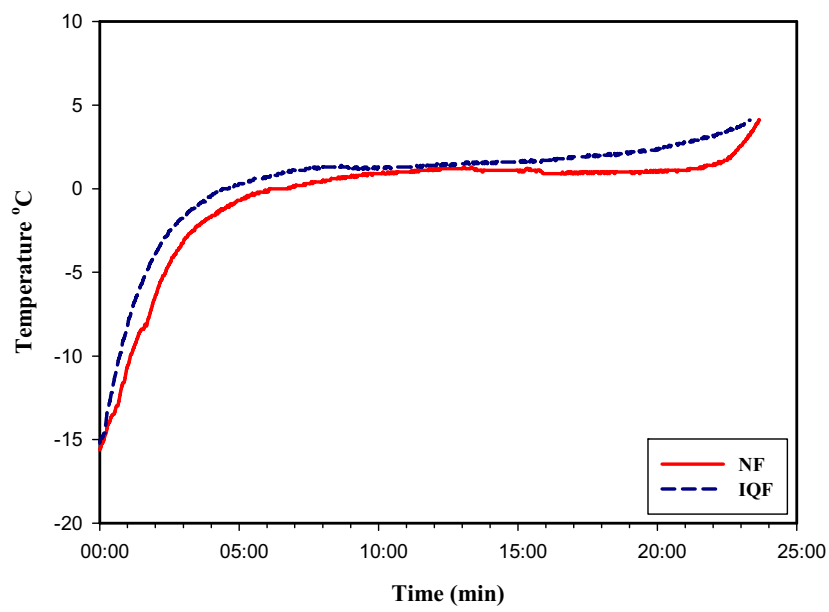

(B)
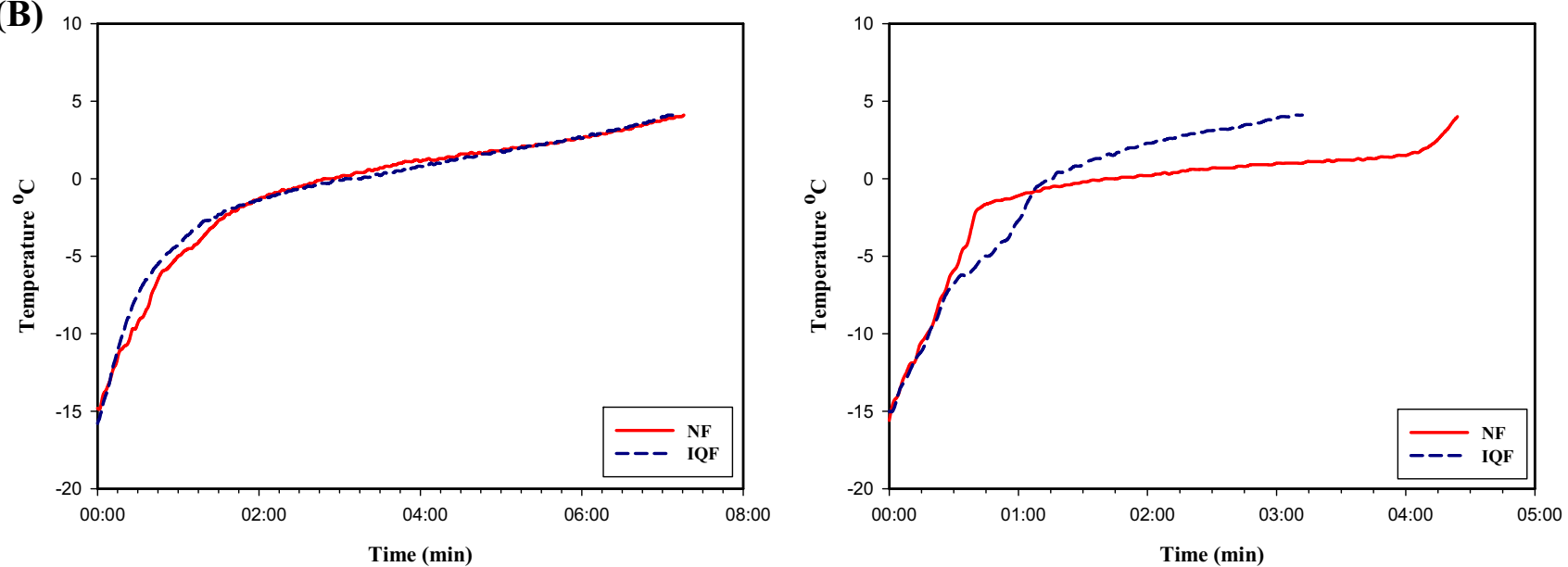

(C)
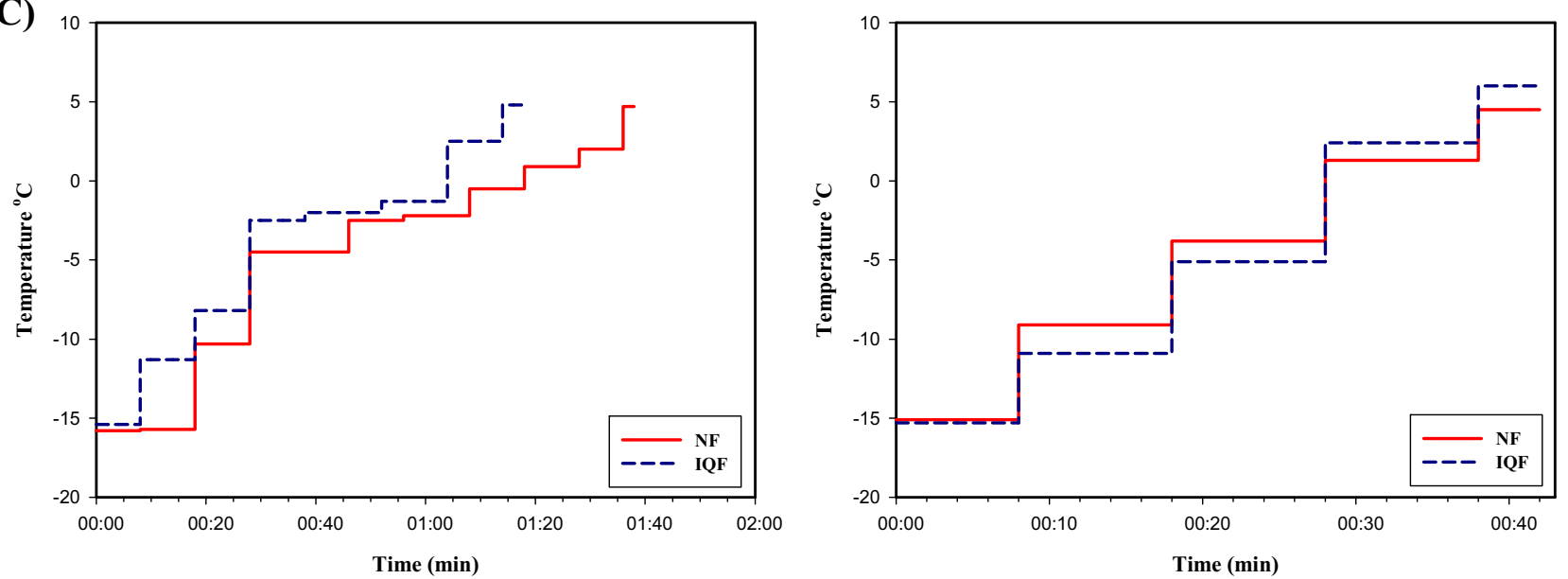

Fig. 1 Thawing curve for different thawing methods. (A) NT (natural air convection thawing); (B) FT (flowing water thawing); (C) MT (microwave thawing). NF Natural freezing, $I Q F$ Individually quick-frozen

IQF samples. IQF can be strongly associated with the formation of small intracellular ice crystals, while, on the contrary, ice crystals are developed in the extracellular space, resulting in the increased drip loss after thawing process as a consequence of slow freezing [9, 17]. Formation of large ice crystal is the main reason for a broken 
(A)

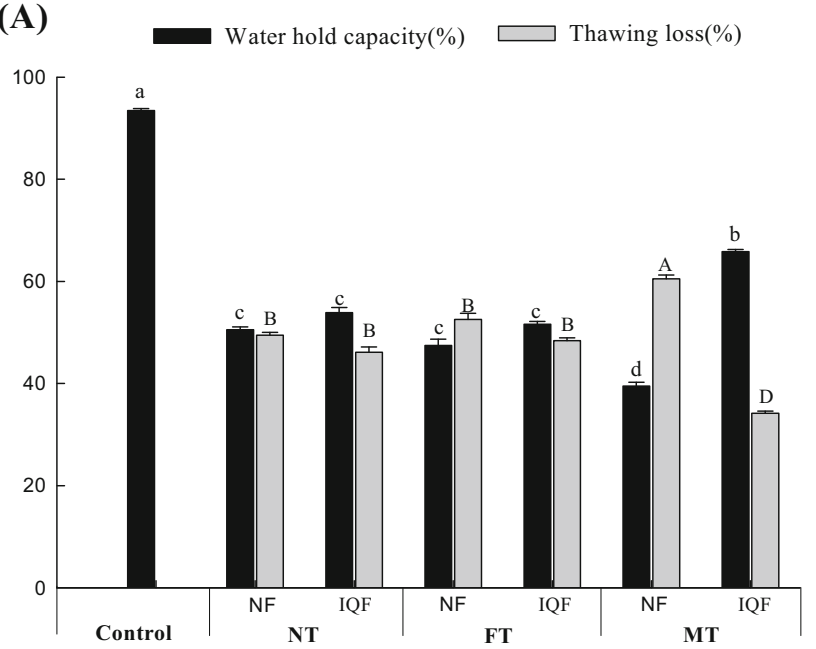

Fig. 2 Effect of different freezing and thawing methods on water holding capacity (\%) and thawing loss (\%) of mushroom. (All samples were thawed until sample's core temperature reached $4{ }^{\circ} \mathrm{C}$ ). (A) mini mushroom; (B) diced mushroom. a-d The different letters are statistically significantly at $p<0.05$ with control. A-D: The

cell well when frozen by NF, but IQF could reduce the formation of large ice crystal; consequently, cell damage could be controlled at the mushroom processing stage [13].

\section{Cutting force analysis}

Figure 3 shows the hardness of mini and diced mushrooms, which were processed by different freezing and thawing methods. The thawing method had little effect on the postthawing hardness of IQF samples. In case of NT, FT, and MT, the hardness of mini and diced mushrooms frozen by

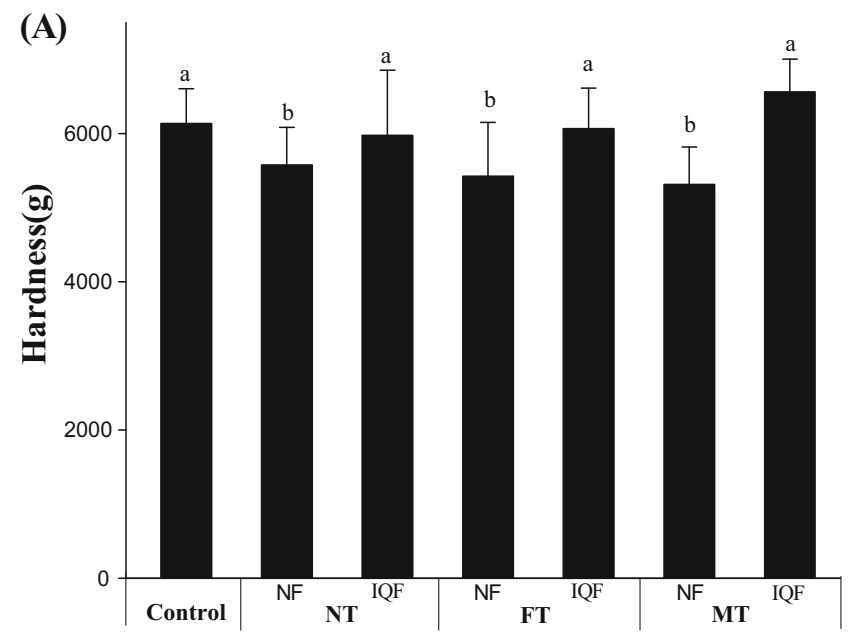

Fig. 3 Effects of different freezing and thawing methods on hardness of mini and diced mushrooms. a-c: The different letters are statistically significantly at $p<0.05$ with control. (A) Mini mushroom; (B) diced mushroom. Control: fresh mushroom; NT natural air
(B)

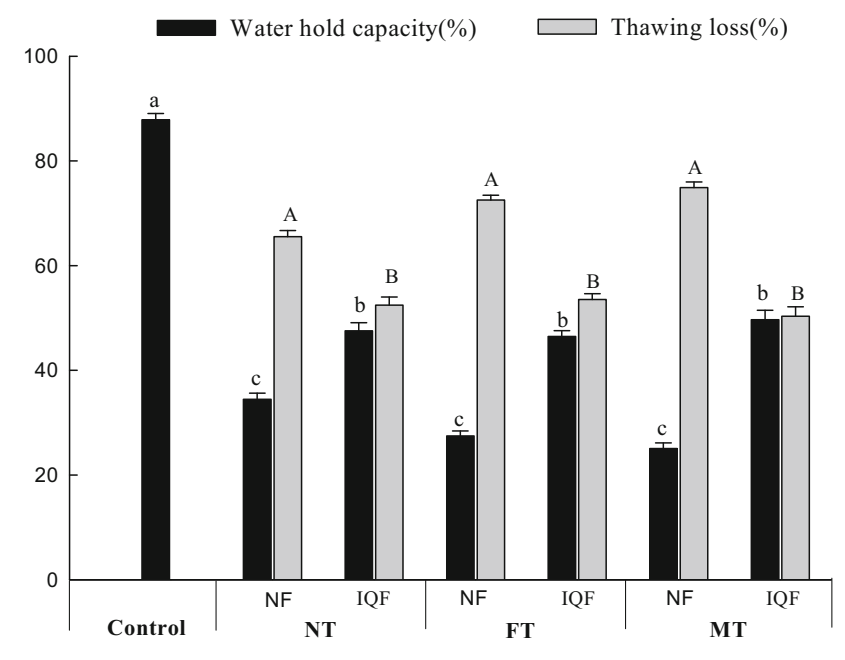

different letters are statistically significantly at $p<0.05$. Control: fresh mushroom; $N T$ natural air convection thawing; $F T$ flowing water thawing; $M T$ microwave thawing; $N F$ natural freezing; $I Q F$ individually quick-frozen

IQF was not significantly different compared with that of the control, whereas the hardness of mushrooms frozen by $\mathrm{NF}$ was significantly lower than that of the control. Freezing rate mainly affects the texture of frozen foods that influences the consumers [15]. Compared with that of other thawing methods, the freezing rate after MT of the diced mushroom samples frozen by NF was significantly lower than that of samples frozen by IQF. The hardness of NT was less than that of FT, which may be because the sample tissue was softened excessively, when heated in a microwave oven [11]. Additionally, it was reported that most of

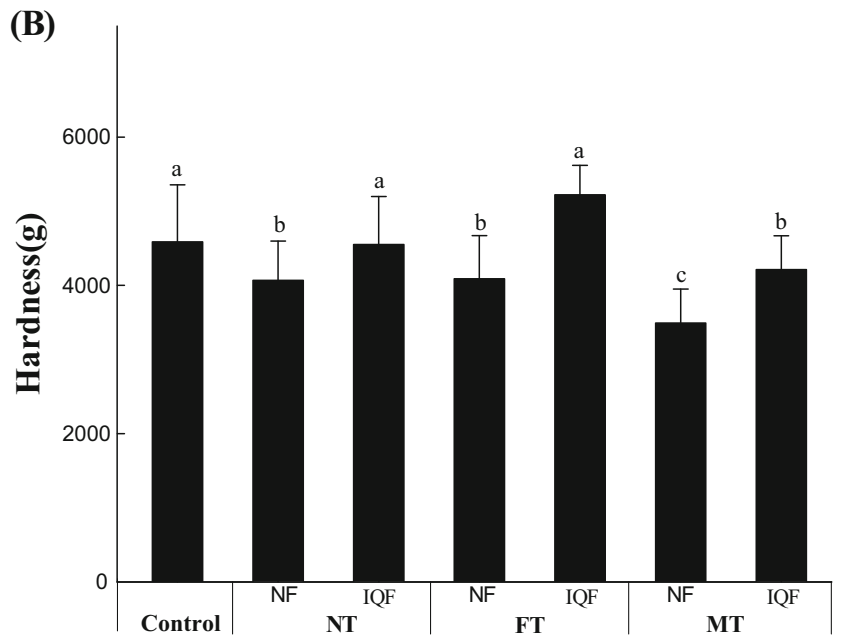

convection thawing; $F T$ flowing water thawing; $M T$ microwave thawing; $N F$ natural freezing; $I Q F$ individually quick-frozen 


\section{Mini mushroom}
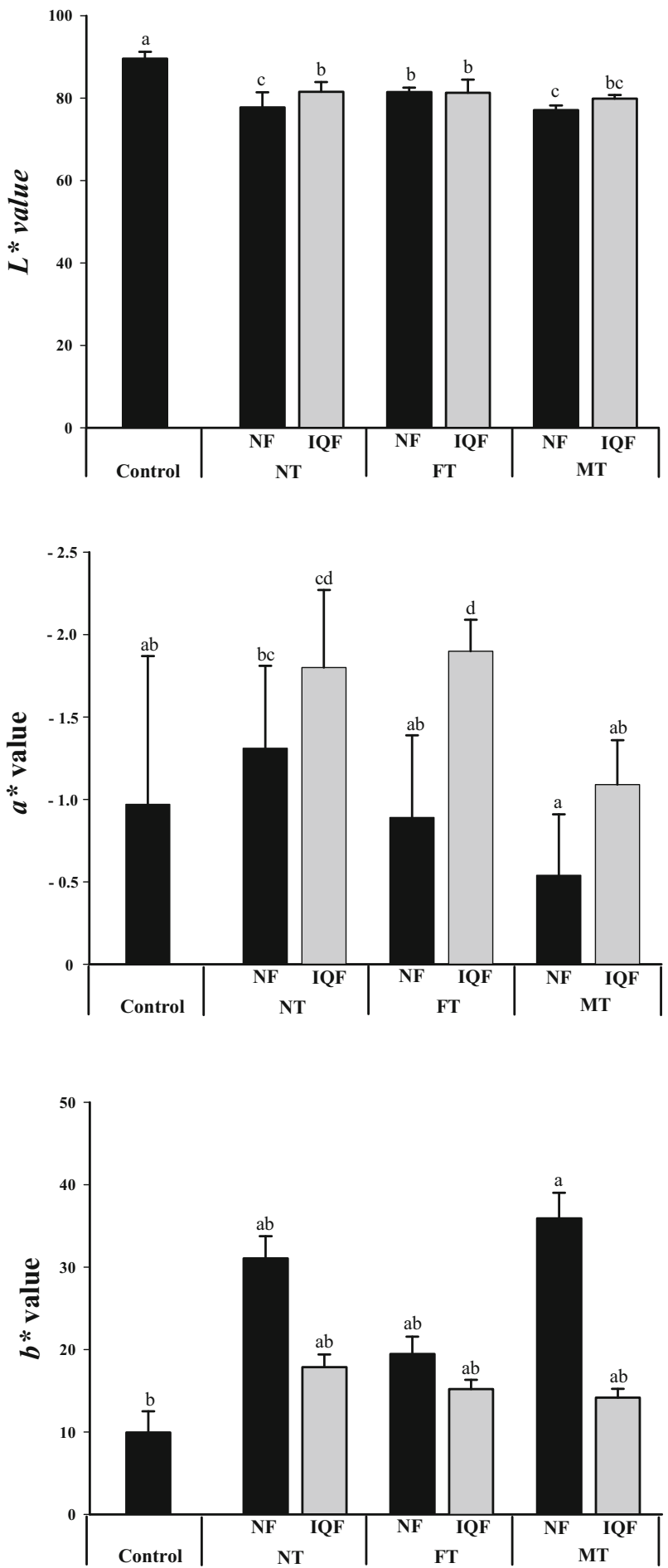

Fig. 4 Effects of different freezing and thawing methods on color of mini and diced mushrooms. Values were expressed as mean \pm standard deviation (S.D) of three measurements. $L^{*}$ means lightness; positive $\alpha^{*}$ corresponded to red color, otherwise to green color; positive $b^{*}$ corresponded to yellow color, otherwise to blue color. a-d
Diced mushroom
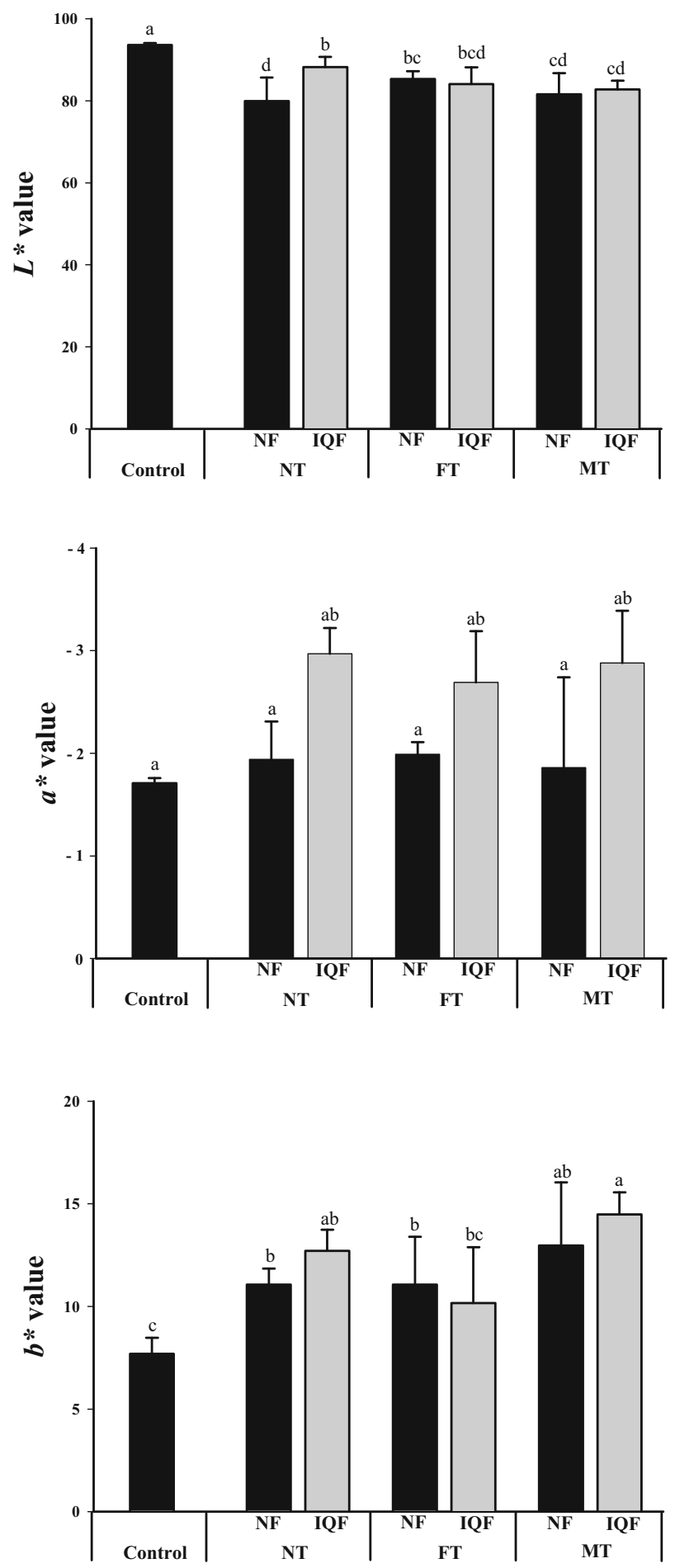

Different letters in the same column indicate statistical difference $(p<0.05)$. Control: fresh mushroom; $N T$ natural air convection thawing; FT flowing water thawing; $M T$ microwave thawing; $N F$ natural freezing; $I Q F$ individually quick-frozen 
the loss happened during the freezing process. Hardness was affected by the size of the crystals. IQF can be associated with the formation of small intracellular ice crystals, thus increasing the hardness $[13,15,29]$. In this study, hardness of mini and diced mushrooms was lost during thawing, but a significantly high hardness value of IQF samples was observed. This result showed that IQF technology is an effectual method, which can maintain the texture of mushrooms when stored [30].

\section{Color analysis}

The effects of different freezing and thawing methods on color parameters are presented in Fig. 4. In case of NT, FT, and MT, the $L^{*}$ value of mini mushrooms was not significantly different after freezing by IQF. However, in case of NF samples, the $L^{*}$ value after NT and MT was lower than that after FT. The $a^{*}$ value of samples with FT after NF, and those with MT after IQF, did not show significant difference compared with that of the control. The $b^{*}$ value of NT, FT, and MT after IQF was closest to that of the control.

In case of the diced mushroom, the $L^{*}$ value of NT, FT, and MT was shown to be significantly lower than that of the control. The $a^{*}$ value of samples after each thawing method was not significantly different compared with that of the control. These results showed that IQF and NT combination is better than that of other freezing and thawing methods; our results were compatible with those of Shim et al. [11] and Liang et al. [15] who report color changed of IQF litchi and Lentinula edodes mushroom after thawing.

\section{Microstructure analysis}

The SEM micrograph of mini mushrooms frozen by different freezing methods was assessed. The results of microstructure analysis are presented in Figs. 5 and 6. According to Yoon [31], cell tissue is damaged on freezing.
Distribution, number, and size of ice crystals were affected by freezing conditions considerably and shorter response time of freezing could, generally, help form smaller ice crystals $[13,15]$. Figure 5 shows that the pore unit area in the structure of IQF sample was lesser than that in the structure of NF sample. Although the textural structure was broken after NT, FT, and MT, the integrity after NT was the best (Fig. 6). The structure of samples frozen by NF was collapsed after FT (Fig. 6D). SEM images were exactly consistent with those in the results of cutting force analysis.

In this study, the embedded pores and interconnected solid networks were observed in the SEM images. The largest pore size was observed in the microstructural properties (wall thickness and pore diameter), which were processed by NF, and the smallest pores appeared under IQF conditions. These results agree with those reported by Harnkarnsujarit et al. [32] who observed that the lower freezing temperature and faster freezing rate could limit the generation of large ice crystals resulting in less damage to the cells.

\section{Sensory evaluation of thawed mushroom}

Color, flavor, and characteristic changes are important influencing factors for selecting products; therefore, sensory evaluation became a critical element in food marketing [15]. Table 1 shows the preference values for sensory parameters of frozen mushroom, such as appearance, color, hardness, mushroom flavor, and overall preference, after NT, FT, and MT. Overall, mini and diced mushroom IQF samples were superior to NF samples in all the aspects. Color and flavor influence consumer behavior the most [15]. In case of appearance, diced mushroom IQF sample thawed by NT showed the highest value. In each group, the color of FT samples was significantly higher than the other IQF and NF samples. Additionally, mini and diced mushroom IQF samples had significantly higher hardness than that of the NF samples. A distinct change in tissue samples
(A)

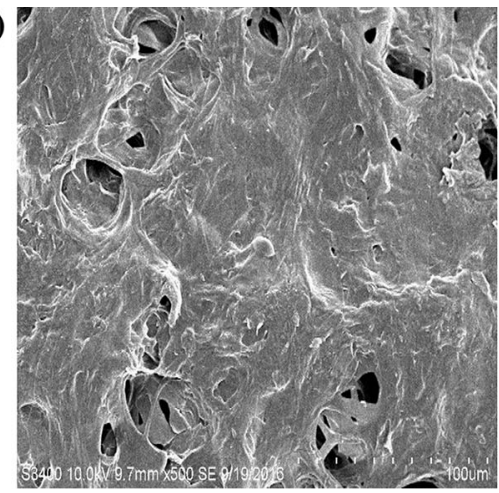

(B)

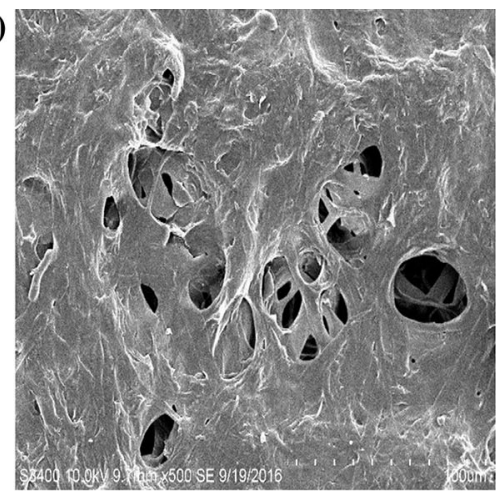

(C)

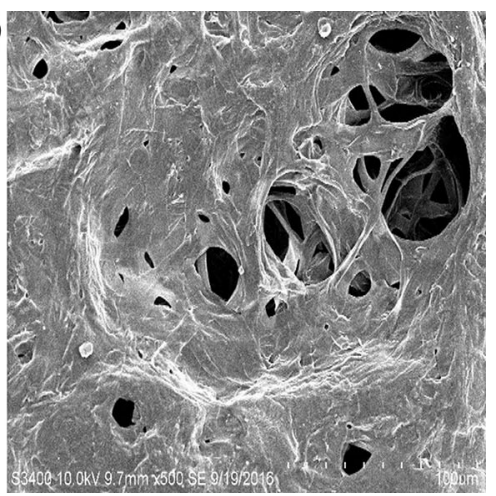

Fig. 5 SEM micrographs of mini mushrooms with different freezing methods. (A) Fresh mushroom; (B) IQF mushroom; (C) NF mushroom 
Fig. 6 SEM micrographs of IQF and NF mini mushrooms with different thawing methods. (A) NT (natural air convection thawing); (B) FT (flowing water thawing); (C) MT (microwave thawing)
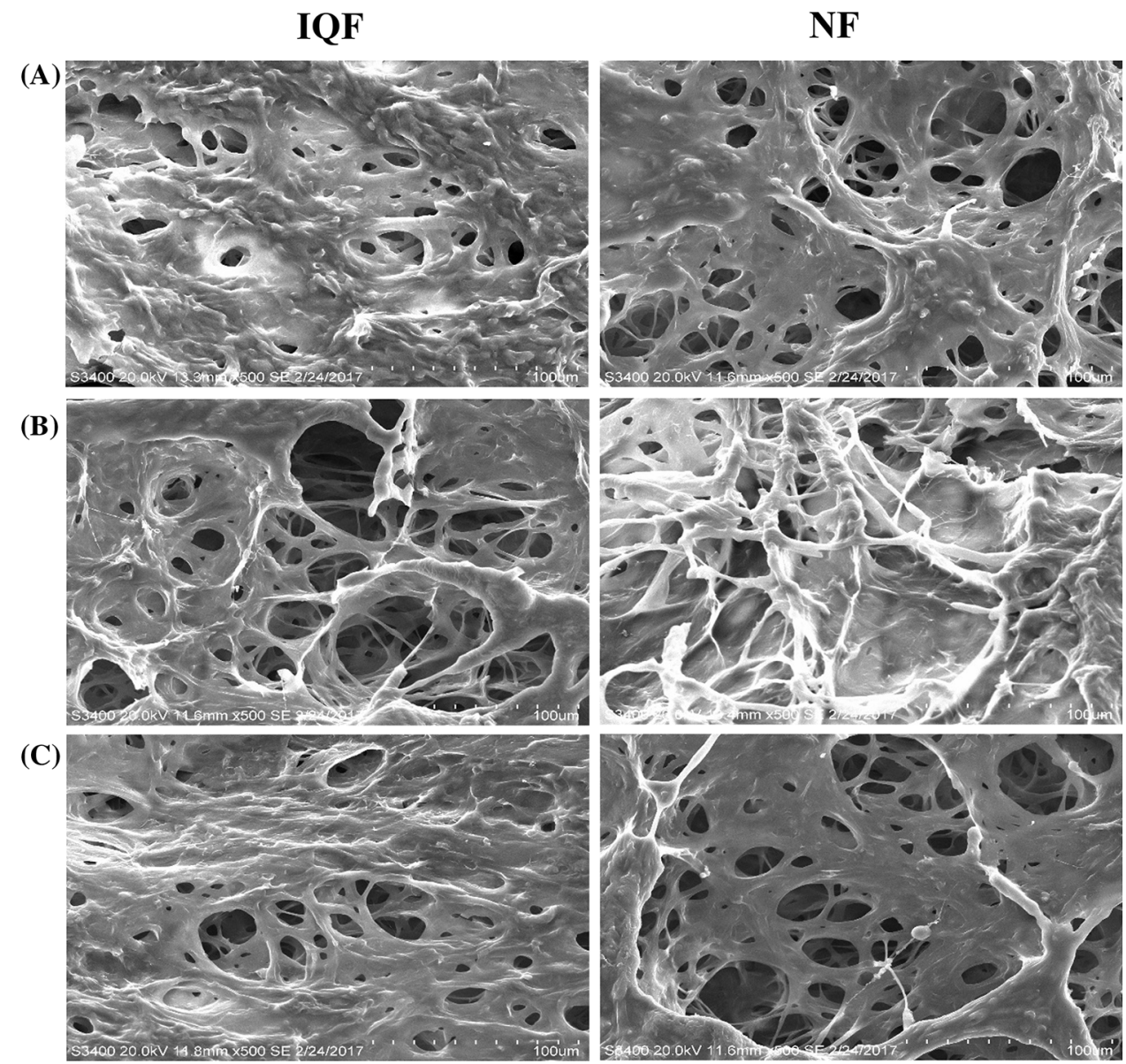

Table 1 Sensory evaluation of thawed mini and diced mushroom

\begin{tabular}{|c|c|c|c|c|c|c|c|}
\hline \multicolumn{3}{|l|}{ Thawing type } & \multirow{2}{*}{$\frac{\text { Appearance }}{4.95 \pm 0.69^{\mathrm{bf}}}$} & \multirow{2}{*}{$\begin{array}{l}\text { Color } \\
4.60 \pm 0.75^{\mathrm{a}}\end{array}$} & \multirow{2}{*}{$\begin{array}{l}\text { Hardness } \\
5.45 \pm 0.60^{\mathrm{a}}\end{array}$} & \multirow{2}{*}{$\begin{array}{l}\text { Mushroom flavor } \\
4.95 \pm 0.83^{\mathrm{b}}\end{array}$} & \multirow{2}{*}{$\begin{array}{l}\text { Overall preference } \\
5.58 \pm 0.60^{\mathrm{ab}}\end{array}$} \\
\hline Mini mushroom & $\mathrm{IQF}$ & NT & & & & & \\
\hline & & FT & $5.80 \pm 0.77^{\mathrm{a}}$ & $5.00 \pm 0.73^{\mathrm{a}}$ & $5.25 \pm 0.72^{\mathrm{a}}$ & $4.25 \pm 0.97^{\mathrm{c}}$ & $5.95 \pm 0.60^{\mathrm{a}}$ \\
\hline & & MT & $4.30 \pm 0.98^{c}$ & $4.65 \pm 0.59^{\mathrm{a}}$ & $4.65 \pm 0.59^{b}$ & $5.60 \pm 0.68^{\mathrm{a}}$ & $3.85 \pm 0.75^{\mathrm{c}}$ \\
\hline & $\mathrm{NF}$ & NT & $3.55 \pm 0.51^{\mathrm{d}}$ & $3.05 \pm 0.60^{\mathrm{c}}$ & $3.75 \pm 0.64^{\mathrm{c}}$ & $3.15 \pm 0.67^{\mathrm{d}}$ & $3.55 \pm 0.83^{\mathrm{c}}$ \\
\hline & & FT & $3.55 \pm 0.60^{\mathrm{d}}$ & $3.70 \pm 0.73^{\mathrm{b}}$ & $3.40 \pm 0.68^{\mathrm{d}}$ & $3.05 \pm 0.76^{\mathrm{d}}$ & $3.60 \pm 0.68^{\mathrm{c}}$ \\
\hline & & MT & $3.35 \pm 0.75^{\mathrm{d}}$ & $2.65 \pm 0.81^{\mathrm{c}}$ & $3.95 \pm 0.76^{\mathrm{c}}$ & $3.95 \pm 0.83^{\mathrm{c}}$ & $2.65 \pm 0.59^{\mathrm{d}}$ \\
\hline \multirow[t]{6}{*}{ Diced mushroom } & IQF & NT & $6.40 \pm 0.60^{\mathrm{a}}$ & $4.05 \pm 0.61^{\mathrm{b}}$ & $6.15 \pm 0.59^{\mathrm{a}}$ & $5.60 \pm 0.94^{\mathrm{a}}$ & $6.40 \pm 0.60^{\mathrm{a}}$ \\
\hline & & FT & $5.30 \pm 0.73^{\mathrm{b}}$ & $4.85 \pm 0.81^{\mathrm{a}}$ & $5.05 \pm 0.83^{\mathrm{b}}$ & $3.90 \pm 0.78^{\mathrm{c}}$ & $5.35 \pm 0.67^{\mathrm{b}}$ \\
\hline & & MT & $4.25 \pm 0.79^{c}$ & $3.35 \pm 0.49^{c}$ & $4.15 \pm 0.81^{\mathrm{cd}}$ & $5.15 \pm 0.75^{\mathrm{ab}}$ & $4.45 \pm 0.51^{\mathrm{c}}$ \\
\hline & $\mathrm{NF}$ & NT & $3.40 \pm 0.99^{\mathrm{d}}$ & $1.50 \pm 0.51^{\mathrm{d}}$ & $3.60 \pm 1.14^{\mathrm{de}}$ & $4.75 \pm 0.85^{\mathrm{b}}$ & $3.15 \pm 0.59^{\mathrm{d}}$ \\
\hline & & FT & $4.40 \pm 0.75^{\mathrm{c}}$ & $4.25 \pm 0.64^{\mathrm{b}}$ & $3.95 \pm 0.82^{\mathrm{d}}$ & $3.00 \pm 0.65^{\mathrm{d}}$ & $4.10 \pm 0.79^{c}$ \\
\hline & & MT & $2.85 \pm 0.59^{\mathrm{e}}$ & $2.95 \pm 0.76^{\mathrm{c}}$ & $3.15 \pm 0.59^{\mathrm{e}}$ & $3.55 \pm 1.05^{\mathrm{c}}$ & $3.30 \pm 0.73^{\mathrm{d}}$ \\
\hline
\end{tabular}

$I Q F$ individually quick-frozen, $N F$ natural freezing, $N T$ natural air convection thawing, $F T$ flowing water thawing, $M T$ microwave thawing ${ }^{\mathrm{a}-\mathrm{e}}$ Different letters within same column mean statistically different at $p<0.05$

${ }^{\mathrm{f}}$ Mean \pm SD of triplicate determinations

was observed in SEM images after thawing, and it directly influenced hardness. The flavor of mushroom samples with
MT after IQF and NF was significantly higher than that with NT and FT. The overall preference of IQF samples 
was significantly higher than that of NF. Sensory quality provides an important reference for producers to determine the shelf life and establish consumption guidance for marketing [12]. Among freezing approaches, IQF least affected the quality after thawing. IQF mushroom, as a new type of IQF product for consumers, will benefit from a good market strategy. IQF could preserve the quality of $P$. eryngii mushrooms during thawing. This study showed that the IQF technology can be used as a new preservation and distribution method of mushroom.

\section{References}

1. Li T, Lo YM, Moon BK (2014) Feasibility of using Hericium erinaceus as the substrate for vinegar fermentation. LWT Food Sci Technol 55:323-328

2. Synytsya A, Míčková K, Synytsya A, Jablonský I, Spěváček J, Erban V, Kováríková E, Čopíková J (2009) Glucans from fruit bodies of cultivated mushrooms Pleurotus ostreatus and Pleurotus eryngii: structure and potential prebiotic activity. Carbohydr Polym 76:548-556

3. Ribeiro B, Pinho PGD, Andrade PB, Baptista P, Valentao P (2009) Fatty acid composition of wild edible mushrooms species: a comparative study. Microchem J 93:29-35

4. Ragunathan R, Gurusamy R, Palaniswamy M, Swaminathan K (1996) Cultivation of Pleurotus spp. On various agro-residues. Food Chem 55:139-144

5. Moonmoon M, Uddin MN, Ahmed S, Shelly NJ, Khan MA (2010) Cultivation of different strains of king oyster mushroom (Pleurotus eryngii) on saw dust and rice straw in Bangladesh. Saudi J Biol Sci 17:341-345

6. Ro HS, Kim SS, Ryu JS, Jeon CO, Lee TS, Lee HS (2007) Comparative studies on the diversity of the edible mushroom Pleurotus eryngii: iTS sequence analysis, RAPD fingerprinting, and physiological characteristics. Mycol Res 111:710-715

7. Kalać P (2009) Chemical composition and nutritional value of European species of wild growing mushroom: a review. Food Chem 113:9-16

8. Singh P, Langowsiki HC, Wani AA, Saengerlaub S (2010) Recent advances in extending the shelf life of fresh Agaricus mushroom: a review. J Sci Food Agric 90:1393-1402

9. Moon B, Lo YM (2014) Conventional and novel applications of edible mushrooms in today's food industry. J Food Process Pre S 38:2146-2153

10. Xin Y, Zhang M, Xu BG, Adhikari B, Sun JC (2015) Research trends in selected blanching pretreatments and quick freezing technologies as applied in fruits and vegetables: a review. Int $\mathbf{J}$ Refrig 57:11-25

11. Shim JB, Jo YJ, Choi MJ, Min SG, Yoo SM, Chun JY (2015) Potential combination of various freezing and thawing techniques applicable for frozen storage of mushroom (Lentinula edodes). Food Eng Prog 19(3):218-225

12. Czapski J, Szudyga K (2000) Frozen mushrooms quality as affected by strain, flush, treatment before freezing, and time of storage. J Food Sci 65(4):722-725

13. Paciulli M, Ganino T, Pellegrini N, Rinaldi M, Zaupa M, Fabbri A, Chiavaro E (2015) Impact of the industrial freezing process on selected vegetables-part I. Structure, texture and antioxidant capacity. Food Res Int 74:329-337
14. Cai C, Miao H, Qian H, Yao Y, Wang B, Wang Q (2016) Effects of industrial pre-freezing processing and freezing handling on glucosinolates and antioxidant attributes in broccoli florets. Food Chem 210:451-456

15. Liang DW, Lin FY, Yang GM, Yue XJ, Zhang QK, Zhang ZQ, Chen HB (2015) Advantages of immersion freezing for quality preservation of litchi fruit during frozen storage. LWT Food Sci Technol 60:948-956

16. Schmidt BM, Erdman JW, Lila MA (2005) Effects of food processing on blueberry antiproliferation and antioxidant activity. J Food Sci 70(6):389-394

17. Holzwarth M, Korhummel S, Carle R, Kammerer DR (2012) Evaluation of the effects of different freezing and thawing methods on color, polyphenol and ascorbic acid retention in strawberries (Fragaria $\times$ ananassa Duch.). Food Res Int 48:241-248

18. Kurz C, Carle R, Schieber A (2008) Characterisation of cell wall polysaccharide profiles of apricots (Prunus armeniaca L.), peaches (Prunus persica L.), and pumpkins (Cucurbita sp.) for the evaluation of fruit product authenticity. Food Chem 106:421-430

19. Oliveira A, Alexandre EMC, Coelho M, Barros RM, Almeida DPF, Pintado M (2016) Peach polyphenol and carotenoid content as affected by frozen storage and pasteurization. LWT Food Sci Technol 66:361-368

20. Ex MK, Gupta SK, Mittal TC, Sharma SR (2016) Influence of storage temperatures on the protein content of french beans (Phaseolus vulgaris L.). Asian J Dairy Food Res 35 (2): 164-167

21. Hatha AAM, Paul N, Rao B (1998) Bacteriological quality of individually quick-frozen (IQF) raw and cooked ready-to-eat shrimp produced from farm raised black tiger shrimp (Penaeus monodon). Food Microbiol 15:177-183

22. Jacobsen S, Fossan KM (2001) Temporal variations in the glaze uptake on individually quick frozen prawns as monitored by the CODEX standard and the enthalpy method. J Food Eng 48:227-233

23. Ko WC, Liu WC, Tsang YT, Hsieh CW (2007) Kinetics of winter mushrooms (Flammulina velutipes) microstructure and quality changes during thermal processing. J Food Eng 81:587-598

24. Jaworska G, Bernas E, Mickowska B (2011) Effect of production process on the amino acid content of frozen and canned Pleurotus ostreatus mushrooms. Food Chem 125:936-943

25. Kim JH, Min SG, Choi MJ, Yoo SM, Jo YJ, Chun JY (2015) Effect of various freezing and thawing methods on physicochemical characterization of carrot. Food Eng Prog 19(4):306-312

26. Arumuganathan $T$, Manikantan MR, Indurani C, Rai RD, Kamal S (2010) Texture and quality parameters of oyster mushroom as influenced by drying methods. Int Agrophys 24:339-342

27. Abbott JA (1999) Quality measurement of fruits and vegetables. Postharvest Biol Technol 15:207-225

28. Alvarez MD, Canet W (1997) Effect of pre-cooling and freezing rate on mechanical strength of potato tissues (cv Monalisa) at freezing temperatures. Z Lebensm Unters F A 204:356-364

29. Hartel RW (2007) The crystalline state. In: Aguilera JM, Lillford PJ (eds) Food materials science: principles and practice. Springer, Berlin, pp 45-65

30. Choi MH, Kim GH (2013) Quality changes in oyster mushrooms during modified atmosphere storage as affected by temperatures and packaging materials. Korean J Food Sci Technol 35(6):1079-1085

31. Yoon KS (2002) Texture and microstructure properties of frozen chicken breasts pretreated with salt and phosphate solutions. Poultry Sci 81(12):1910-1915

32. Harnkarnsujarit N, Kawai K, Watanabe M, Suzuki T (2016) Effects of freezing on microstructure and rehydration properties of freeze-dried soybean curd. J Food Eng 184:10-20 